\title{
Los orígenes del cooperativismo de crédito en Argentina, 1887-1926
}

\section{The Origins of Credit Cooperatives in Argentina, 1887-1926}

\author{
Andrés Spognardi* \\ Centro de Estudos Sociais-Universidade de Coimbra, Coimbra, Portugal, \\ email: aspognardi@ces.uc.pt
}

Resumen: Las cooperativas de crédito argentinas dieron sus primeros pasos entre 1887 y 1926, al amparo de un marco legal impreciso. La pobre caracterización de la sociedad cooperativa en el código de comercio de 1889, y la falta de una legislación y regulación adecuada en el sistema financiero, dieron lugar a la aparición de una variedad de iniciativas, no siempre inspiradas por el espíritu de solidaridad y ayuda recíproca. El presente artículo ofrece un panorama general de aquellas experiencias pioneras. Combinando fuentes primarias y secundarias, se identifican y describen los rasgos esenciales de las entidades fundadas antes de la sanción de la primera Ley de Cooperativas, a finales de 1926. El estudio también discute los principales cambios introducidos por esa norma, examinando sus efectos inmediatos sobre la estructura del sector.

Palabras clave: cooperativas; crédito; marco legal; Argentina.

Abstract: Argentina's credit co-operatives took their first steps between 1887 and 1926, under the umbrella of an imprecise legal framework. The poor characterization of the co-operative society in the commercial code of 1889 , together with the lack of proper legislation and regulations in the financial system, led to the emergence of a variety of initiatives, not always inspired by the spirit of solidarity and mutual assistance. This article provides an overview of those pioneering experiences. By combining primary and secondary sources, it identifies and describes the essential features of the credit co-operatives established before the passing of the first Co-operatives Act, in late 1926. The study also discusses the key changes introduced by this law, analyzing their shortterm effects on the sector's structure.

Key words: co-operatives; credit; legal framework; Argentina.

Fecha de recepción: 26 de abril de 2016. Fecha de aceptación: 18 de agosto de 2016.

* Investigador de postdoctorado de la Fundação para a Ciência e a Tecnologia de Portugal (FCT), Programa Operacional Capital Humano ( $\mathrm{POCH}$ ). Agradezco a los evaluadores anónimos de este trabajo, cuyas atentas observaciones y oportunas sugerencias han ayudado a mejorar sustancialmente la primera versión del manuscrito. 


\section{INTRODUCCIÓN}

$\mathrm{E}$ ntre principios de la década de 1880 y finales de la de 1920, Argentina vivió una de las etapas de mayor expansión económica de su historia. La fuerte entrada de capitales extranjeros y la exportación de productos primarios se tradujeron en un aumento de la masa de fondos prestables y de las oportunidades de inversión, estimulando un rápido desarrollo de la actividad financiera. A su vez, la llegada masiva de inmigrantes contribuyó a poblar el territorio e imprimió un cierto dinamismo al comercio, los servicios y la pequeña industria doméstica.

Las transformaciones sociales y las oportunidades y desafíos creados por el crecimiento y por la inmigración favorecieron también la incorporación de ideas económicas innovadoras. En ese contexto, hacia fines de la década de 1880 comenzaron a aparecer algunas entidades de crédito constituidas por los propios oferentes y demandantes de servicios financieros, inspiradas en las sociedades cooperativas que por entonces funcionaban en Europa. ${ }^{1}$

Las instituciones del país, sin embargo, no lograron ajustarse con celeridad suficiente a los cambios sociales y económicos de la época. La falta de una legislación adecuada y la escasa regulación estatal en el sector financiero determinaron una confusión entre finalidades solidarias y comerciales, y conspiraron contra la consolidación de un movimiento de crédito cooperativo articulado.

Desde la fundación de los primeros bancos cooperativos, en 1887, hasta la entrada en vigor de una ley que consagraría el carácter no lucrativo del sector, en 1926, el cooperativismo de crédito atrajo a un conjunto variopinto de actores económicos, inspirados por los más diversos intereses. Iniciativas de cooperación genuina, orientadas a resolver las dificultades de acceso a la financiación bancaria que padecían algunos segmentos específicos de la sociedad, se entremezclaron con otras formadas por oportunistas, orientadas a la captura de rentas y a la realización de operaciones especulativas.

Hasta el momento este conjunto heterogéneo de experiencias pioneras no ha recibido debida atención por parte de la literatura. Algunos autores han abordado la cuestión de una manera tangencial, que proporciona una imagen parcial, focalizada en específicos grupos sociales, regiones geográficas o entidades cooperativas (Auza, 1987; Ballent, 1988; Feierstein, 2006; Mirelman, 1990; Niklison, 1920; Reula, 1969; Zadoff, 2005). Por su parte, los principales estudios sobre el cooperativismo argentino se han limitado

\footnotetext{
${ }^{1}$ Para una descripción del contexto social y económico en el que surgieron las cooperativas de crédito europeas, véase Birchall (2013).
} 
a ofrecer algunas referencias anecdóticas aisladas (Borea, 1917; Cavallone, 1947, p. 182; Grela, 1965, pp. 72-73; Rosso 1942, pp. 344-346), o se han concentrado en los desarrollos que siguieron a la implementación de la Ley de Cooperativas de 1926 (Bonaparte, 1989; Brauner, 2007; Gleizer, 1981; Kampel y Vuotto, 2000; Mizrahi, 1976; Plotinsky, 2011; Schujman, 1979; Verbeke, 2005).

El presente estudio pretende cubrir esta laguna. Al combinar el análisis de fuentes primarias con aportaciones de la literatura secundaria, el trabajo traza un panorama general del cooperativismo de crédito argentino durante su etapa inicial; también analiza la naturaleza de los cambios normativos introducidos en 1926 y sus impactos a corto plazo sobre la estructura del sector.

Para cumplir con estos objetivos, el texto ha sido dividido en cuatro secciones. La primera discute las imprecisiones contenidas en el marco legal del sector cooperativo y financiero durante el periodo analizado; se hace hincapié en las dificultades que tales imprecisiones plantean para el abordaje del cooperativismo de crédito como objeto de estudio y se identifican los criterios metodológicos utilizados para afrontarlas. La segunda parte presenta una caracterización general de las cooperativas de crédito fundadas entre 1887 y 1926, agrupándolas en diferentes clases y categorías de interés analítico. La tercera parte analiza el destino de aquellas primeras cooperativas; se presta especial atención a las modificaciones introducidas por la Ley de Cooperativas de 1926 y a su impacto sobre las entidades que funcionaban en ese momento. La conclusión sintetiza los principales resultados del estudio y evidencia algunos aspectos que requieren de un análisis más minucioso.

\section{LA DELIMITACIÓN DEL COOPERATIVISMO DE CRÉDITO EN UN CONTEXTO JURÍDICO IMPRECISO}

La ausencia de investigaciones acerca de lo que puede denominarse "fase inicial" del cooperativismo de crédito en Argentina (1887-1926) refleja, probablemente, las dificultades prácticas que plantea el estudio de emprendimientos económicos desarrollados en el contexto de un marco legal ambiguo y permisivo.

La primera legislación en materia cooperativa fue introducida por la reforma del código de comercio de 1889, cuando el sector se encontraba en estado embrionario. Preocupado por no obstaculizar su desarrollo, el codificador consideró prudente evitar una reglamentación minuciosa y prefirió limitarse a delinear algunos aspectos generales de la figura societa- 
ria. ${ }^{2}$ Las disposiciones, que entraron en vigor en mayo de 1890 y rigieron hasta diciembre de 1926, obligaron a las cooperativas a expresar en el acto constitutivo las condiciones de admisión y cese o exclusión de los socios, y el monto mínimo y la modalidad de integración del capital social (art. 393). También establecieron que la denominación de la sociedad debía ser acompañada por las palabras "cooperativa limitada" o "cooperativa ilimitada", según el tipo de responsabilidad asumida por los socios (art. 392), y que las acciones -en caso de ser emitidas- debían ser nominales y asegurar el derecho a un solo voto por asociado (art. 394). Más allá de este último precepto, tendente a garantizar la naturaleza democrática del proceso decisional, las cooperativas podían operar como cualquier sociedad comercial (art. 392), generando y distribuyendo lucros entre sus asociados.

Las indefiniciones en el plano financiero contribuyeron a exacerbar esta confusión entre aspectos solidarios y lucrativos. Durante el periodo bajo estudio no existió una ley integral, específicamente orientadas a regular y controlar la actividad de los intermediarios financieros; tampoco existió un organismo estatal encargado de coordinar las políticas relacionadas con la moneda y el crédito. ${ }^{3}$

La ausencia de una autoridad monetaria favoreció el comportamiento procíclico de la actividad financiera. La fuerte entrada de capitales extranjeros -ligada a inversiones y empréstitos del exterior y a la exportación de productos primarios- se tradujo en aumentos del circulante que estimularon la proliferación de bancos y sociedades de crédito. Las interrupciones en ese flujo de fondos externos -motivadas por factores exógenos o por problemas relacionados con el funcionamiento de la economía doméstica- resultaron en una contracción de la actividad financiera, con serios efectos negativos sobre las variables reales de la economía.

Entre 1887 y 1926 se produjeron dos interrupciones de ese tipo. La primera, ocurrida en 1890, estuvo vinculada al desmesurado aumento de la base monetaria y del endeudamiento del sector público y privado, y derivó en una crisis profunda que obligó a una reconfiguración estructural del sistema monetario y bancario durante los años sucesivos. ${ }^{4}$ La segunda, ocurrida en 1914, estuvo en mayor medida asociada a los efectos contrac-

\footnotetext{
${ }^{2}$ Véanse De las sociedades cooperativas (cap. VI) y De las compañías o sociedades (libro II, título III), Código de Comercio de 1889 (República Argentina, 1889). Acerca de las justificaciones de esta solución legal, véase Escalante, Zeballos, Basualdo y Colombres (1889, p. XXIX).

${ }^{3}$ Las primeras normas en esta materia fueron sancionadas en 1935 . Al respecto, véanse las leyes 12.155 y 12.156 del 28 de marzo de 1935, Boletín Oficial de la República Argentina (5 de abril de 1935). Sobre el funcionamiento del sistema financiero argentino durante el periodo bajo estudio, véase Della Paolera y Taylor (2001, cap. 1).

${ }^{4}$ La crisis financiera de 1890 derivó en la creación de una Caja de Conversión (encargada de mantener el circulante en proporción a las reservas externas) y en la refundación del banco estatal bajo el nombre de Banco de la Nación Argentina.
} 
tivos de la primera guerra mundial sobre el comercio y el crédito internacional, aunque en opinión de algunos observadores reflejó también el temor de los inversores externos por el excesivo dinamismo de la actividad financiera doméstica (Nakamura y Zarazaga, 2001). ${ }^{5}$

Por otra parte, durante el periodo bajo estudio, la escasez de medidas oficiales tendentes a orientar el crédito hacia las necesidades de la economía real favoreció el desarrollo de actividades especulativas. Una parte considerable de los fondos prestables no fue dirigida hacia la inversión productiva, sino hacia colocaciones financieras con fines de especulación, dejando así insatisfechos algunos segmentos importantes de la demanda de crédito. Como han apuntado distintos autores, la falta de financiamiento a largo plazo para la pequeña y mediana industria y las dificultades del pequeño productor agropecuario para acceder al sistema bancario tradicional fueron dos problemas recurrentes de la economía, incluso durante las fases expansivas del ciclo económico (Accose, 1935; Rougier, 1999).

\section{Criterios para una definición de "cooperativa de crédito"}

En principio resulta difícil establecer cuáles fueron los efectos de la desorganización del sistema financiero y de las imprecisiones contenidas en el código de comercio sobre el desarrollo del cooperativismo de crédito. Por un lado, es posible que varias cooperativas hayan surgido como genuinos instrumentos de ayuda recíproca entre individuos pertenecientes a los sectores económicos que se hallaban marginados del circuito bancario tradicional. Por el otro, sin embargo, también es posible que varias cooperativas hayan sido concebidas como instrumentos para la captación de rentas financieras en el curso de una onda especulativa.

Las ambigüedades apenas referidas dificultan la identificación del cooperativismo de crédito como unidad de análisis. Durante el periodo bajo estudio, sociedades eminentemente lucrativas pudieron ser constituidas bajo la forma cooperativa; a la vez, organizaciones con características asimilables a la cooperativa pueden haber sido constituidas bajo otras figuras societarias.

De manera ideal, la individualización de las entidades que corresponden a la definición tradicional de cooperativa ${ }^{6}$ exigiría la realización de un estudio particularizado de las operaciones efectivamente realizadas por (2001).

${ }^{5}$ Sobre las causas y consecuencias de las crisis de 1890 y 1914, véase Della Paolera y Taylor

${ }^{6}$ Acerca de la definición tradicional de cooperativa, véase Macpherson (1995). 
cada una de ellas. ${ }^{7}$ Desafortunadamente, las características de la información disponible tornan inviable esta posibilidad y obligan a la adopción de un criterio arbitrario. Así, en este estudio se consideran como "cooperativas" a todas las entidades que fueron reconocidas como tales por los organismos competentes del estado nacional y de las diferentes provincias. Naturalmente esta decisión metodológica comporta importantes limitaciones; sin embargo, por los motivos expuestos, se trata de la única estrategia viable para trazar los contornos del sector cooperativo en su etapa inicial.

Una dificultad analítica adicional deriva de la falta de regulaciones financieras, traducida en la ausencia de parámetros que permitan distinguir claramente entre los diferentes tipos de emprendimientos operantes en el sector crediticio (bancos, sociedades de inversión, sociedades de crédito para la edificación, etc.). En este caso, para identificar las cooperativas operantes en el sector financiero se tiene en cuenta el objeto social principal de la empresa, tal como emerge de la lectura de sus estatutos o de su denominación social. De este modo, el estudio incluye a las cooperativas dedicadas principalmente a la recepción de depósitos y/o concesión de préstamos con finalidades diversas (consumo, vivienda, etc.), generalmente establecidas bajo el nombre de "banco" o "sociedad de crédito". ${ }^{8}$

\section{Fuentes de información}

Otro aspecto ligado a la indefinición del marco legal que complica considerablemente la investigación es la ausencia de un registro unificado y exhaustivo de sociedades cooperativas. La información relativa a las entidades constituidas durante este periodo se encuentra dispersa en una gran variedad de documentos emanados por el Estado nacional y las diferentes provincias. En el presente estudio se han revisado los registros oficiales de la República Argentina (en donde constan los decretos de aprobación de estatutos de las empresas radicadas en la capital federal y de las gobernaciones de Chaco y Misiones) y los registros de las provincias de Buenos Aires y Santa Fe (Archivo General de la Provincia de Santa Fe; Boletín Oficial de la República Argentina, 1912-1940; Buenos Aires [BA], 1888-1942; Ministerio de Justicia e Instrucción Pública, 1887-1929; República Argentina [RA], 1888-1938, 1897-1911). Para la identificación de las cooperativas radicadas en centros urbanos de otras provincias y en colonias rurales del

\footnotetext{
${ }^{7}$ La simple lectura de los estatutos sociales no permite dirimir la cuestión, ya que las finalidades en ellos esbozadas no siempre se corresponden con las prácticas empresariales efectivas.

${ }^{8}$ La definición excluye a las cooperativas de propósitos múltiples dotadas de una sección de créditos accesoria a la actividad principal.
} 
interior, se ha recurrido a diversas fuentes primarias y secundarias (Anuario Kraft, 1942; Anuario Veritas (años); Auza, 1987; Boletín Oficial de la Bolsa de Comercio de Buenos Aires; Borea, 1917; Dorr, 1948; Museo Social Argentino, 1916, 1920, 1921; Niklison, 1920; Serralunga, 1920a, 1920b). Con el fin de minimizar la posibilidad de omisiones, las fuentes citadas han sido cotejadas con los datos de una serie de publicaciones oficiales (periódicas y ocasionales), en las que se listan las principales entidades dedicadas a la actividad bancaria (Agote, 1881-1888; Carranza, 1904-1912; Comisión Nacional del Censo, 1917; Dirección General de Estadística, 1926; Dirección General de Estadística Municipal, 1891-1914; Terry, 1894).

\section{UN CUADRO GENERAL DE LAS COOPERATIVAS DE CRÉDITO ESTABLECIDAS ENTRE 1887 Y 1926}

Los criterios delineados en la sección anterior han permitido identificar 94 cooperativas de crédito, establecidas entre abril de 1887 y diciembre de 1926 (véase el listado completo en el Apéndice). ${ }^{9}$ Si se tiene en cuenta la naturaleza del proceso en el que fueron constituidas, en una primera aproximación estas entidades pueden ser clasificadas en dos clases. La primera -que denominaremos "espontáneas"- incluye a 61 sociedades surgidas por la iniciativa autónoma de las personas que integraban su base social. La segunda -que denominaremos "inducidas"- comprende 33 cajas rurales de tipo Raiffeisen, ${ }^{10}$ formadas por colonos del interior del país, bajo los auspicios de una asociación de laicos católicos radicada en la ciudad de Buenos Aires (véase gráfica 1).

La distinción apenas esbozada refleja también importantes diferencias en términos del origen social, los objetivos perseguidos y la estructura societaria adoptada por las cooperativas. Las entidades espontáneas fueron formadas por grupos pertenecientes a estratos sociales altos y medios, con capacidad para movilizar una masa considerable de ahorros. Casi sin excepciones, su capital estaba compuesto por acciones nominativas, integradas en dinero por sus asociados, quienes respondían por las operaciones realizadas por la sociedad hasta el monto de las acciones suscritas. Su es-

\footnotetext{
${ }^{9}$ Los estatutos de la Sociedad Cooperativa Caja de Créditos Israelita de La Plata fueron aprobados por el gobierno bonaerense mediante un decreto fechado diez días después de la entrada en vigor de la Ley de Cooperativas de 1926 (Decreto s. n. del 30 de diciembre de 1926, en BA, año 1926, vol. 2, p. 648). Dicha sociedad es incluida en el presente estudio porque la solicitud para la aprobación de sus estatutos fue presentada antes de la sanción de la Ley de Cooperativas. ${ }^{10}$ A lo largo del presente texto, las expresiones cooperativas Raiffeisen, cajas rurales y cooperativas inducidas se utilizan como sinónimos. Para una breve descripción del modelo de cooperativa Raiffeisen, véase Kalmi (2013, pp. 57-59).
} 


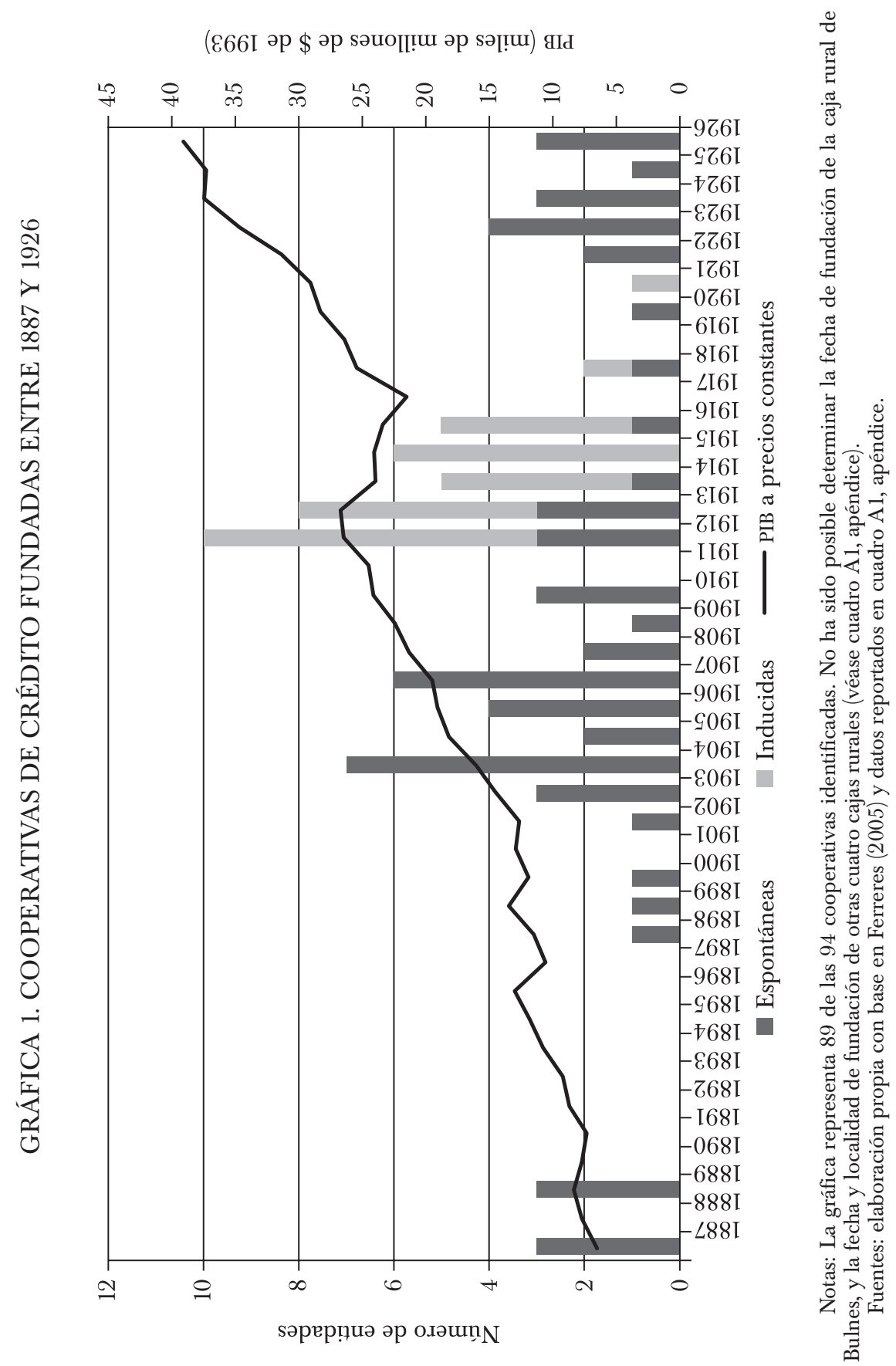


tablecimiento coincidió con tres periodos caracterizados por un fuerte crecimiento del producto interno bruto (1887-1889, 1898-1913 y 1918-1926) (véase gráfica 1). La ausencia de entidades espontáneas durante los años que siguieron a las crisis de 1890 y 1914 refuerza la idea de un comportamiento pro-cíclico; sobre la base de esta relación, nuestra hipótesis es que la mayor parte de estas cooperativas habrían sido concebidas como instrumentos para canalizar recursos relativamente abundantes hacia actividades especulativas (por parte de oportunistas), o productivas (por parte de individuos que tenían dificultades para acceder al circuito bancario tradicional)..$^{11}$

Las cooperativas inducidas, en cambio, fueron promovidas por una organización externa. La gráfica 1 muestra que su fundación se concentró especialmente en el quinquenio 1912-1916; como se discutirá más adelante, ese periodo coincidió con la etapa inicial -y la más intensa- de la campaña propagandística emprendida por sus impulsores. A diferencia de lo que ocurría en las cooperativas espontáneas, los asociados de las cooperativas inducidas eran pequeños arrendatarios rurales, titulares de un capital reducido, generalmente limitados a unos pocos instrumentos, animales de labranza y a la promesa de una futura cosecha (Seguí, 1898). Dado que la capacidad de ahorro de estos productores era exigua, el capital social de estas cooperativas no estaba constituido por acciones en dinero, sino por la suma de los patrimonios poseídos individualmente (animales, herramientas, insumos, etc.). Utilizando el conjunto de esos patrimonios como garantía, las entidades negociaban contratos de crédito y arrendamiento con la banca comercial y con los grandes terratenientes; tales operaciones eran efectuadas "por cuenta de todos" y los socios respondían solidaria e ilimitadamente por cada uno de los contratos celebrados (Serralunga, 1920a).

\section{Impulsores de las cooperativas espontáneas: elites, empleados y judios}

Si se examina la nómina de sus fundadores y principales dirigentes, la mayor parte de las cooperativas espontáneas pueden ser asociadas a tres sectores o grupos sociales diferentes. El primero comprende a reconocidas figuras de la elite política, intelectual y económica argentina (dirigentes

${ }^{11}$ Una hipótesis alternativa señala que algunas de estas entidades podrían haber sido creadas como instrumentos anticíclicos durante particulares coyunturas negativas de las economías regionales. Richard-Jorba (2008), por ejemplo, sugiere que la fundación de las cooperativas Banco Industrial y Comercial de Mendoza (1904), Banco del Este (1904) y Banco Popular de Mendoza (1905) podría haber estado relacionada a la crisis que atravesó la vitivinicultura mendocina entre 1901 y 1903. Sería interesante explorar la validez de esta hipótesis, extendiendo también el análisis al caso de otras cooperativas del interior identificadas en este artículo. 
partidarios, diplomáticos, profesionales, masones, académicos, funcionarios públicos, comerciantes e industriales); la lista también abarca políticos y empresarios influyentes a nivel provincial o local, cuyos nombres aparecen en revistas de sociedad y finanzas, anuarios comerciales, memorias empresariales, compilaciones biográficas y otras fuentes secundarias. ${ }^{12} \mathrm{El}$ segundo grupo incluye a individuos pertenecientes a un mismo oficio o categoría profesional; la mayoría eran trabajadores de reparticiones estatales radicadas en la ciudad de Buenos Aires, tales como el Ministerio de Agricultura, las obras sanitarias, los ferrocarriles, la policía, y las escuelas (Congreso Nacional, 1904, p. 563; Crisol, octubre de 1920, núm. 4, pp. 14-19; Ministerio de Justicia e Instrucción Pública, 1887-1929, t. I, p. 45; Moirano, 1948; Rodríguez, 1975, pp. 392-393; Seijo, 1937). Finalmente, el tercer grupo está compuesto por pequeños productores y comerciantes de origen judío askenazí, cuyas cooperativas llevaban la palabra "israelita" en su denominación social. ${ }^{13}$

Sobre la base de las distinciones apenas esbozadas, las entidades espontáneas han sido divididas en tres categorías, denominadas respectivamente: "elites", "empleados" y "judíos" (véase cuadro 1). Asimismo, bajo la designación "otros" se enlistan diez sociedades que no han podido ser asignadas a ninguno de los agrupamientos anteriores. ${ }^{14}$ Considerando su razón social y el nombre de los dirigentes que suscribían sus balances, es posible intuir que no se trata de cooperativas de empleados o judíos. Es probable que hayan sido fundadas por personajes pertenecientes a las "elites" locales o provinciales -empresarios, políticos o intelectuales cuyos nombres no aparecen en las fuentes de información consultadas. ${ }^{15}$

Como muestra el cuadro 1, la fundación de las cooperativas de la categoría "elites" se concentró especialmente en el periodo 1898-1913. En aquel momento, el crecimiento de las exportaciones y la sustancial mejora en los términos del intercambio acentuaban el ritmo de la expansión monetaria (Nakamura y Zarazaga, 2001). Al mismo tiempo, el diferencial existente entre la tasa de interés y la tasa de aumento del valor de la tierra favorecía el desarrollo de operaciones especulativas vinculadas al mercado

${ }^{12}$ Véanse las fuentes del cuadro A1, apéndice.

${ }^{13}$ La única excepción a esta regla está constituida por la cooperativa Caja Rural de Villa Clara, fundada por inmigrantes judíos residentes en la colonia del mismo nombre. Véase Tiempo, febrero de 1985 , núm. 189 , p. 9 .

${ }^{14}$ Los grupos comprendidos en el cuadro 1 resultan de una categorización de la clase "espontáneas", realizada en función de ciertas similitudes en la composición de los sectores sociales que las impulsaron. A diferencia de las clases resultantes de una clasificación, los grupos que emergen de esta categorización no son mutuamente excluyentes. Sobre las diferencias entre clasificación y categorización, véase Jacob (2004).

${ }^{15}$ Las similitudes en la distribución temporal y espacial de los grupos "otras" y "elite" parecen reforzar la plausibilidad de esta hipótesis (véase cuadro 1, líneas 1 y 4). 


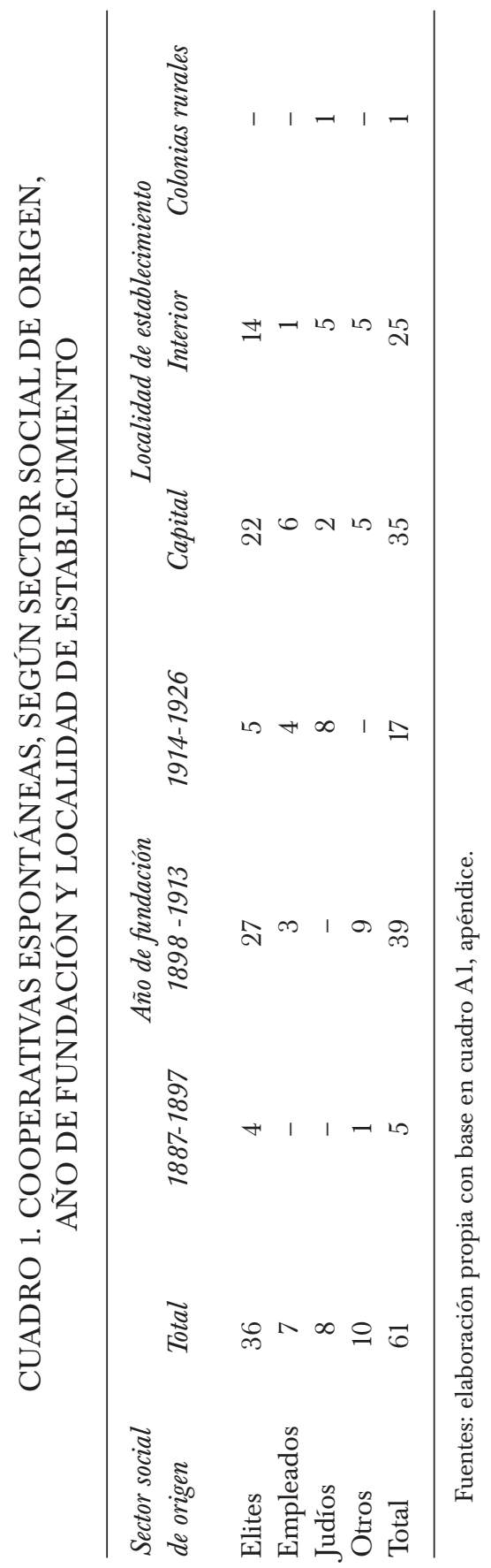


inmobiliario (Adelman, 1990), y estimulaba un desacople creciente entre las variables financieras y reales de la economía. ${ }^{16}$

$\mathrm{Si}$ a las condiciones del contexto económico se suman las imprecisiones del cuadro normativo del cooperativismo emergen algunas dudas acerca de la naturaleza de los objetivos que inspiraban el funcionamiento de estas entidades. En otras palabras, cabe preguntarse si las cooperativas impulsadas desde algunos de los sectores más pudientes de la sociedad estaban genuinamente inspiradas en los principios de la solidaridad y la ayuda recíproca, o si por el contrario funcionaban como instrumentos para la apropiación de beneficios individuales.

Desafortunadamente, el carácter limitado de la información disponible impide evaluar la situación particular de cada cooperativa. Sin embargo, si se toman como referencia algunos casos emblemáticos -para los cuales existen datos fehacientes- el grupo en cuestión revela una heterogeneidad considerable. En un extremo es posible identificar entidades auténticamente solidarias como El Hogar Obrero. Esta sociedad, que representó la principal iniciativa del partido socialista en el campo de la cooperación, tenía por objetivo mejorar las condiciones habitacionales de los trabajadores residentes en la ciudad de Buenos Aires al otorgar créditos blandos para la adquisición de la vivienda propia. ${ }^{17}$ En cambio, en el extremo opuesto, se colocan entidades como El Hogar Argentino -una cooperativa espuria fundada por un grupo de empresarios y políticos poderosos ${ }^{18}$ que llegó incluso a financiar la adquisición de tierras y la construcción de edificios mediante la emisión de acciones en los mercados bursátiles europeos (Ballent, 1988; Vida Financiera, 20 de octubre de 1913, núm. 29, p. 1).

Retornando a los datos reportados en el cuadro 1, se advierte la menor importancia cuantitativa de las cooperativas formadas por empleados y judíos. En conjunto, ambas categorías representan menos de la mitad de las cooperativas agrupadas bajo la denominación "elites". En términos cualitativos, sin embargo, los grupos en cuestión muestran una conside-

${ }^{16}$ Entre 1900 y 1912 la tasa de crecimiento de los depósitos y los préstamos en los bancos privados prácticamente duplicó la tasa de crecimiento del producto interno bruto (Nakamura y Zarazaga, 2001, p. 25).

${ }^{17}$ Entre los dirigentes y militantes que promovieron su establecimiento, puede mencionarse a los diputados Juan B. Justo y Nicolás Repetto, y al dirigente sindical Adrián Patroni (Repetto, 1944). Para un análisis del papel de esta cooperativa en el acceso a la vivienda de los sectores populares, véase Ballent (1988).

${ }^{18}$ Entre los fundadores de El Hogar Argentino se encontraban el ex ministro de finanzas de la provincia de Buenos Aires, Julián Balbín; el ex contador general del Banco de la Provincia de Buenos Aires, Enrique Condomí; y los hacendados Antonino Ferrari y Nicolás Videla, quienes también habían ocupado altos cargos legislativos y ejecutivos en el gobierno provincial (Congreso Nacional, 1916, p. 306; The Argentine Yearbook, 1903, p. 367). 
rable homogeneidad interna, caracterizada por una neta prevalencia de finalidades solidarias.

Las cooperativas de empleados surgieron a partir de la primera década del siglo XX, por iniciativa de un sector de la sociedad que contaba con ingresos relativamente altos, suficientes para movilizar una masa consistente de ahorros. ${ }^{19}$ En su funcionamiento combinaban algunas operaciones características de la intermediación bancaria, tales como la recepción de depósitos y el otorgamiento de créditos para el consumo y la edificación, con otras típicamente mutualistas. Sus asociados podían contribuir a la constitución de fondos solidarios contra enfermedad, invalidez, vejez y muerte (Congreso Nacional, 1904; Moirano, 1948; Museo Social Argentino, 1916; Rodríguez, 1975; Seijo, 1937), o bien participar en actividades de formación técnica y otros eventos sociales orientados a "fomentar la unión y el compañerismo" (Crisol, núm. 4, octubre de 1920, pp. 14-19).

Por tratarse de un hecho inusual para la época, resulta interesante destacar que una de las primeras comisiones directivas de la entidad más antigua de este grupo -el Banco Escolar Argentino- contó con la presencia femenina de la profesora Modesta S. de Salas (The Argentine Yearbook, 1907, p. 235). En un contexto histórico caracterizado por la hegemonía de los hombres en el mundo de los negocios, la combinación entre magisterio y cooperativismo parece haber abierto un camino excepcional para la llegada de una mujer a una posición de poder.

Las cooperativas de crédito de origen judío, por su parte, operaban exclusivamente al interior de las comunidades de inmigrantes askenazí, financiando no sólo los emprendimientos productivos de sus miembros -la mayor parte comerciantes, artesanos y pequeños productores rurales-, sino también las actividades y organizaciones culturales, educativas y religiosas de la colectividad (López, 1987, p. 27; Reula, 1969, pp. 262-265). Todas ellas se establecieron en colonias rurales y centros urbanos caracterizados por una fuerte presencia de esa colectividad de inmigrantes, durante el quinquenio comprendido entre 1922 y 1926 (véase cuadro A1, Apéndice).

Las causas de esta aparición relativamente tardía se encuentran en la naturaleza del proceso social que derivó en su constitución. Desde su llegada al país, hacia finales de la década de 1880, los judíos de origen askenazí habían impulsado iniciativas de ayuda recíproca, generalmente estructuradas bajo la forma de círculos informales, asociaciones de soco-

${ }^{19}$ Otras dos entidades con características similares -el Banco Escolar de la Provincia de Buenos Aires y el Banco Escolar de Corrientes- se constituyeron en 1921, aparentemente bajo la figura de la sociedad anónima comercial (Anuario Veritas, 31 de marzo de 1948, núm. 207, p. 637). Véase también Decreto 534 del 16 de agosto de 1921, Registro Oficial de la Provincia de Buenos Aires, julio-diciembre de 1921, p. 1026 (véase Buenos Aires, 1888-1942). 
rros mutuos o cooperativas de propósitos múltiples. En su etapa inicial, esas organizaciones ofrecían una gama de servicios variados, tales como la venta unificada de la producción, la concesión de pequeños anticipos de dinero a corto plazo, y la compra conjunta de máquinas, insumos y artículos de consumo (Feierstein, 2006; Mirelman, 1990). Con el transcurso del tiempo, la relativa prosperidad económica alcanzada por muchos de sus integrantes se tradujo en un incremento de la masa de fondos prestables y de las exigencias de capitales para la inversión. El aumento del volumen y de la complejidad de los servicios financieros demandados favoreció una especialización de la oferta y estimuló a las organizaciones más dinámicas a constituirse formalmente como cooperativa de crédito. ${ }^{20}$

\section{Impulsores de las cooperativas inducidas: la acción social de los laicos católicos}

Las cooperativas "inducidas" fueron promovidas por una asociación de laicos católicos denominada Liga Social Argentina (en adelante LSA), constituida en la ciudad de Buenos Aires en 1908. Inspiradas en la Doctrina Social de la Iglesia, las iniciativas de esta organización apuntaban a mejorar las condiciones de vida de las clases populares y contrarrestar al mismo tiempo la creciente influencia del socialismo ateísta sobre ese segmento de la sociedad.

A diferencia de otras instituciones pioneras del activismo católico argentino -más preocupadas por la cuestión obrera- la labor de la LSA se concentró en el ámbito rural. Por entonces el sector agropecuario presentaba una estructura económica piramidal, caracterizada por una base atomizada, compuesta por pequeños productores desprovistos de tierra y capital, y un vértice integrado por ricos latifundistas y poderosas instituciones bancarias (Seguí, 1898, pp. 365-391). Los intermediarios, que oficiaban como nexo entre la base y el vértice, aprovechaban la debilidad contractual del pequeño productor para establecer condiciones de crédito usurarias y para pactar subarrendamientos por periodos breves, los cuales forzaban al colono a aceptar condiciones leoninas de renovación para no perder las inversiones realizadas en los terrenos.

Con el fin de acabar con estas prácticas de explotación económica y mejorar la calidad de vida en las colonias, la LSA propuso la creación de una red capilar de cajas rurales de tipo Raiffeisen, similares a las que

\footnotetext{
${ }^{20}$ Esta evolución no comportó una apertura hacia otros sectores de la sociedad argentina, ya que en general las cooperativas de crédito judías continuaron operando exclusivamente en el ámbito de las comunidades en las que habían surgido (Mirelman, 1990, pp. 43-45). Véase también Tiempo (núm. 189, febrero de 1985, pp. 8-10).
} 
funcionaban con éxito en varios países europeos. Como se explicó más arriba, este modelo aunaba los pequeños capitales individuales para conectar directamente al colono con el circuito bancario tradicional y con los arrendadores latifundistas. Sin embargo, al igual que la mayor parte de las iniciativas inspiradas en la Doctrina Social de la Iglesia, sus objetivos trascendían el plano económico.

En efecto, el proyecto de la LSA aspiraba también a expandir la influencia del catolicismo en el medio rural, colocando a la religión como piedra angular de un instrumento de emancipación económica. En el modelo de cooperación propuesto por la LSA, la caja rural actuaba "por cuenta de todos" y sus asociados debían responder ilimitadamente con sus propios patrimonios por cada una de las operaciones realizadas. La viabilidad económica de esta estructura societaria requería la existencia de estrechos vínculos de confianza y reciprocidad entre los integrantes de la base social, lo cual, a su vez, justificaba la introducción del principio de homogeneidad religiosa: la adhesión a los valores cristianos de la honestidad, la solidaridad y el bien común eran consideradaos un requisito indispensable para el ingreso del colono a la cooperativa (Serralunga, 1920b, p. 271).

A fin de llevar a la práctica su ambicioso programa, en 1910 los dirigentes de la LSA contrataron a Giuseppe Serralunga Langhi, un abogado italiano que conocía de primera mano la experiencia de los millares de cajas rurales católicas que funcionaban en su país. Serralunga elaboró un estatuto modelo y lideró una delegación que, a partir de 1911, visitó numerosas colonias y pueblos del interior de las provincias de Buenos Aires, Córdoba, Entre Ríos y Santa Fe. Allí, los enviados de la LSA mantuvieron reuniones con los colonos interesados, dictaron conferencias y repartieron folletos explicativos de las ventajas del modelo cooperativo (La Civiltà Cattolica, 15 de marzo de 1913, pp. 755-756).

Los primeros resultados de esta campaña propagandística fueron prometedores. Entre 1912 y 1913 comenzaron a funcionar doce cajas rurales y se presentaron más de un centenar de propuestas para la creación de otras nuevas (Auza, 1987, p. 275). Durante los dos años sucesivos se establecieron otras catorce; sin embargo, a partir de 1917 el ritmo disminuyó considerablemente (véase gráfica 1). En 1918 la LSA intentó recuperar el dinamismo perdido mediante la creación de una organización de segundo grado denominada Sindicato Argentino de las Cajas Rurales (SACR), pero el escaso número de cooperativas adherentes le impidió cumplir eficazmente con aquel objetivo (Auza, 1987, p. 278). 


\section{EL DESTINO DE LAS COOPERATIVAS PIONERAS}

La mayor parte de las cooperativas constituidas entre 1887 y 1926 no lograron arraigarse. Para finales de 1926, un total de 45 entidades habían sido disueltas o transformadas en sociedades anónimas lucrativas (véase cuadro 2).

Resulta importante destacar que el fenómeno de la desaparición de entidades no se distribuyó uniformemente a lo largo de las clases y categorías delineadas en la sección anterior. Casi todas las cooperativas formadas por "empleados" y "judíos" se mantenían operando hacia principios de diciembre de 1926 (véase cuadro 2, segunda columna). Por contraste, para ese momento se verificaron numerosas disoluciones entre el resto de las cooperativas espontáneas (elites y otros) y entre las cooperativas inducidas. Además, varias de las entidades agrupadas bajo la denominación "elites" habían optado por abandonar la figura societaria cooperativa para convertirse en sociedades anónimas comerciales (véase cuadro 2 , tercera columna).

La elevada tasa de disoluciones y transformaciones entre las cooperativas comprendidas en este último grupo (23 sobre un total de 36 ) sugiere que muchos de los emprendimientos habrían sido económicamente frágiles y/o habrían estado inspirados por finalidades que no eran auténticamente solidarias. Varias sociedades cerraron sus puertas poco tiempo después de haber sido constituidas ${ }^{21}$ y hubo incluso casos de cooperativas que ni siquiera llegaron a operar (Quesada, 1894, p. 71). Algunas quiebras estuvieron además acompañadas de acusaciones por estafas y denuncias penales contra los iniciadores y dirigentes (Quesada, 1901, pp. 587-589; República Argentina, 1902, pp. 611-615), lo que refuerza la hipótesis de una difundida instrumentalización de la figura societaria para finalidades especulativas (Borea, 1917, pp. 108-109). ${ }^{22}$

Por su parte, el escaso desarrollo alcanzado por las cooperativas inducidas (apenas 33 llegaron a ser constituidas), sumado al elevado número de disoluciones dentro de esta categoría (14), pone de manifiesto el resultado decepcionante de la campaña de promoción emprendida por la LSA. $\mathrm{Al}$ reflexionar sobre las causas de este fracaso, algunos observadores han apuntado a la supuesta incompatibilidad del modelo Raiffeisen con las condiciones socioeconómicas imperantes en el agro argentino. Desde esta perspectiva, la baja densidad y acentuada diversidad étnica que caracteri-

\footnotetext{
${ }^{21}$ Pueden citarse como ejemplo los casos del Banco Universal, Alcancía Popular, Los Previsores y Banco Gremial (véase cuadro A1, apéndice).

${ }^{22}$ Acerca de la utilización de las cooperativas para finalidades lucrativas, consúltense también las declaraciones del diputado Juan B. Justo en Congreso Nacional (1916, p. 306).
} 
Am. Lat. Hist. Econ., año 24, núm. 2, mayo-agosto, 2017, pp. 201-234

CUADRO 2. SITUACIÓN DE LAS COOPERATIVAS FUNDADAS ENTRE 1887 Y 1926, AL DÍA 1 DE DICIEMBRE DE 1926

\begin{tabular}{lccccc}
\hline Cooperativas & Total & $\begin{array}{c}\text { Continúan } \\
\text { funcionando }\end{array}$ & $\begin{array}{c}\text { Transformadas } \\
\text { en } \text { S. } A \text {. }\end{array}$ & Disueltas & Sin \\
Espontáneas & 61 & 25 & 10 & 21 & 5 \\
Elites & 36 & 10 & 9 & 14 & 3 \\
Empleados & 7 & 5 & 1 & 1 & 0 \\
Judíos & 8 & 8 & 0 & 0 & 0 \\
Otros & 10 & 2 & 0 & 6 & 2 \\
Inducidas (LSA) & 33 & 19 & 0 & 14 & 0 \\
Total & 94 & 44 & 10 & 35 & 5 \\
\hline
\end{tabular}

${ }^{a}$ Para el caso de las cooperativas inducidas, las cifras reportadas en la segunda y cuarta columnas corresponden al año 1920 (véase Niklison, 1920, p. 261).

Fuentes: elaboración propia con base en el cuadro A1, apéndice.

zaba a las poblaciones rurales contribuyó a exacerbar la mentalidad individualista del colono, lo que impidió la formación de los lazos de confianza y reciprocidad que eran necesarios para el buen funcionamiento de las sociedades de responsabilidad ilimitada (Becco, 1938, p. 109; Borea, 1917, pp. 200-201).

Por otra parte, más allá de la plausibilidad de esta interpretación, también es evidente que el desarrollo de las cooperativas inducidas fue afectado por la acción hostil de los intermediarios del negocio agrícola y por la insuficiencia de los recursos abocados a las acciones de promoción y asistencia desplegadas por la LSA. Estos problemas se vieron a su vez agravados por la actitud indiferente de altas jerarquías eclesiásticas y por el escaso apoyo de las diócesis y del clero (Auza, 1987, p. 276; Serralunga, 1920b, p. 270). En 1919, una reorganización de las obras católicas impulsada por las altas esferas del episcopado determinó el cierre de la LSA y la transferencia de sus iniciativas hacia otra institución denominada Liga Económico-Social. Las dificultades organizativas asociadas a esta reestructuración resultaron en la paralización de las obras de promoción y auxilio al cooperativismo y sumieron a las pocas entidades existentes en un gradual e irremediable declino (Auza, 1987, pp. 278-279). 
Los cambios normativos introducidos en 1926 y su impacto sobre las cooperativas subsistentes

Haciendo hincapié en la necesidad de promover el desarrollo del sector y de evitar la desnaturalización de sus finalidades solidarias, entre 1915 y 1925 varios legisladores presentaron proyectos para la modificación del cuadro normativo del cooperativismo. ${ }^{23}$ Esas propuestas fueron luego recogidas por la comisión de códigos del senado, que en 1926 sometió a consideración del parlamento una solución de síntesis articulada en dos textos independientes. El primero de ellos, sancionado a principios de octubre, delineó algunas medidas de fomento. En particular, introdujo una excepción en el reglamento vigente del Banco de la Nación Argentina, autorizándolo a conceder préstamos especiales a las sociedades cooperativas por plazos superiores a los seis meses (art. 1). También eximió a las cooperativas de una serie de impuestos nacionales, incluyendo el papel sellado y la contribución sobre el valor de los edificios y construcciones (art. 5). ${ }^{24}$

El segundo texto, que por una desprolijidad administrativa fue sancionado luego de la entrada en vigor de las medidas de estímulo (Repetto, 1932, p. 271), abrogó las normas del código de comercio e introdujo novedades tendentes a garantizar la finalidad no lucrativa del cooperativismo. ${ }^{25}$ Entre sus disposiciones más importantes, la ley acotó las posibilidades de apropiación individual de beneficios económicos y del capital acumulado por la cooperativa (véase cuadro 3, líneas 1 a 6), y estableció límites a la tasa de interés cobrada en las operaciones de préstamo (cuadro 3, línea 7). En línea con la legislación internacional, la norma también limitó la responsabilidad de los asociados al monto de las acciones integradas y consagró el principio de neutralidad política y religiosa del cooperativismo (cuadro 3, líneas 8 y 9 ). ${ }^{26}$

Las disposiciones sintetizadas en el cuadro 3 tuvieron un impacto profundo e inmediato sobre las 44 entidades subsistentes (véase cuadro 2).

${ }^{23}$ Algunas de las propuestas más interesantes fueron presentadas por los diputados socialistas Juan B. Justo y Nicolás Repetto, quienes además habían participado en la fundación de la cooperativa El Hogar Obrero. Para una descripción de todos los proyectos legislativos que precedieron a la sanción de la Ley 11.388, véanse Bravo (1927) y Repetto (1932, pp. 222-271).

${ }^{24}$ La norma también contenía medidas de estímulo para las cooperativas dedicadas a la industrialización de productos primarios. Al respecto, véase la Ley 11.380 del 5 de octubre de 1926, en Boletín Oficial de la República Argentina, 20 de octubre de 1926.

${ }^{25}$ Ley 11.388 del 20 de diciembre de 1926, en Boletín Oficial de la República Argentina, 27 de diciembre de 1926 .

${ }^{26}$ Con el fin de asegurar el respeto de los preceptos enunciados, el nuevo cuadro legal atribuyó al Ministerio de Agricultura la responsabilidad de revisar y certificar los balances de las cooperativas (art. 10). Este organismo quedó además encargado de mantener un registro de las cooperativas constituidas en todo el territorio argentino, lo que en la práctica significó el inicio de la recopilación sistemática de estadísticas sobre el sector. 


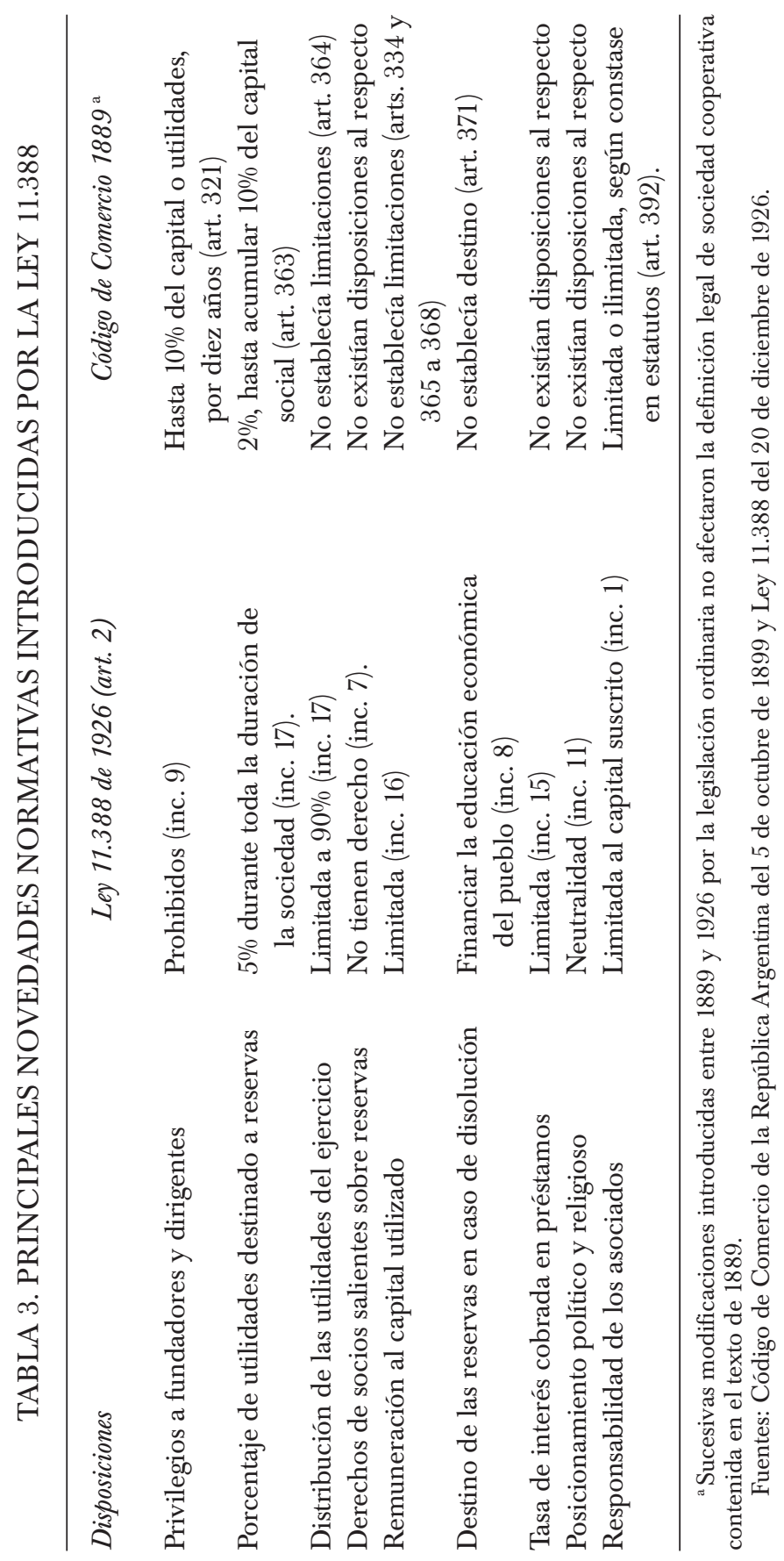


Como explica Tenembaum (1946, p. 232), la incorporación de los principios de neutralidad política y religiosa y la obligatoriedad de la figura de la responsabilidad limitada tornaron inviable el modelo cooperativo Raiffeisen, y motivaron la desaparición definitiva de las pocas cooperativas inducidas que continuaban en actividad.

De acuerdo con los argumentos esgrimidos por la comisión que elaboró el texto de la norma, la responsabilidad limitada apuntaba a garantizar un mayor control de la solvencia de las sociedades, en tanto que la neutralidad política y religiosa buscaba evitar la disgregación y el faccionalismo que evidenciaban algunos movimientos cooperativos extranjeros (Bravo, 1927, pp. 227-228 y 238-240). Sin embargo, más allá de estas justificaciones, no puede descartarse que la solución legislativa haya sido parcialmente motivada por la amenaza que una potencial difusión del cooperativismo de crédito católico representaba para las corrientes liberales y socialistas que por entonces dominaban la escena política nacional (Serralunga, 1920b, p. 271).

Paralelamente, los preceptos tendentes a asegurar el carácter no lucrativo del cooperativismo (cuadro 3, líneas 1 a 7) provocaron mutaciones significativas en un sector de las cooperativas espontáneas. En un lapso relativamente breve, la mayor parte de las entidades agrupadas en las categorías "elites" y "empleados" concretaron su transformación en sociedades anónimas lucrativas (véase cuadro 4 , segunda columna).

Si bien no ha sido posible establecer los factores que motivaron la decisión de cada entidad, el comportamiento observado contribuye a reforzar la hipótesis de una fuerte incidencia de objetivos lucrativos entre las cooperativas de la categoría "elites". ${ }^{27}$ Por el contrario, en el caso de las cooperativas formadas por empleados -surgidas con propósitos esencialmente solidarios- la elevada tasa de transformaciones resulta llamativa. ${ }^{28}$ Aunque la determinación de los factores que subyacen a este curioso fenómeno requeriría la realización de un análisis particularizado, la lectura de un estudio de la época permite esbozar una hipótesis interpretativa (véase Seijo, 1937): es probable que las finalidades mutualistas hayan ganado

${ }^{27}$ En este grupo sólo continuaron operando las cooperativas de crédito para la edificación El Hogar Obrero -como ya se mencionó, ligada al partido socialista- y La Casa Popular Propia -fundada por el empresario italiano Estanislao Bozzi y presidida durante largo tiempo por el industrial Martín E. Quadri, quien durante la década de 1920 integraría además el consejo directivo de la Unión Industrial Argentina (The Review of the River Plate, 17 de agosto de 1923, núm. 1654, p. 389). Vale la pena aclarar que El Hogar Obrero se convertiría gradualmente en una cooperativa de propósitos múltiples (con creciente prevalencia de su sección consumo), por lo cual su desarrollo sucesivo no encuadra dentro de los criterios adoptados en este artículo para delimitar al sector de crédito cooperativo.

${ }^{28}$ La única cooperativa de la categoría empleados subsistente fue una sociedad formada por el personal del Ministerio de Agricultura de la Nación, denominada Banco Ceres (Moirano, 1948, p. 7). 


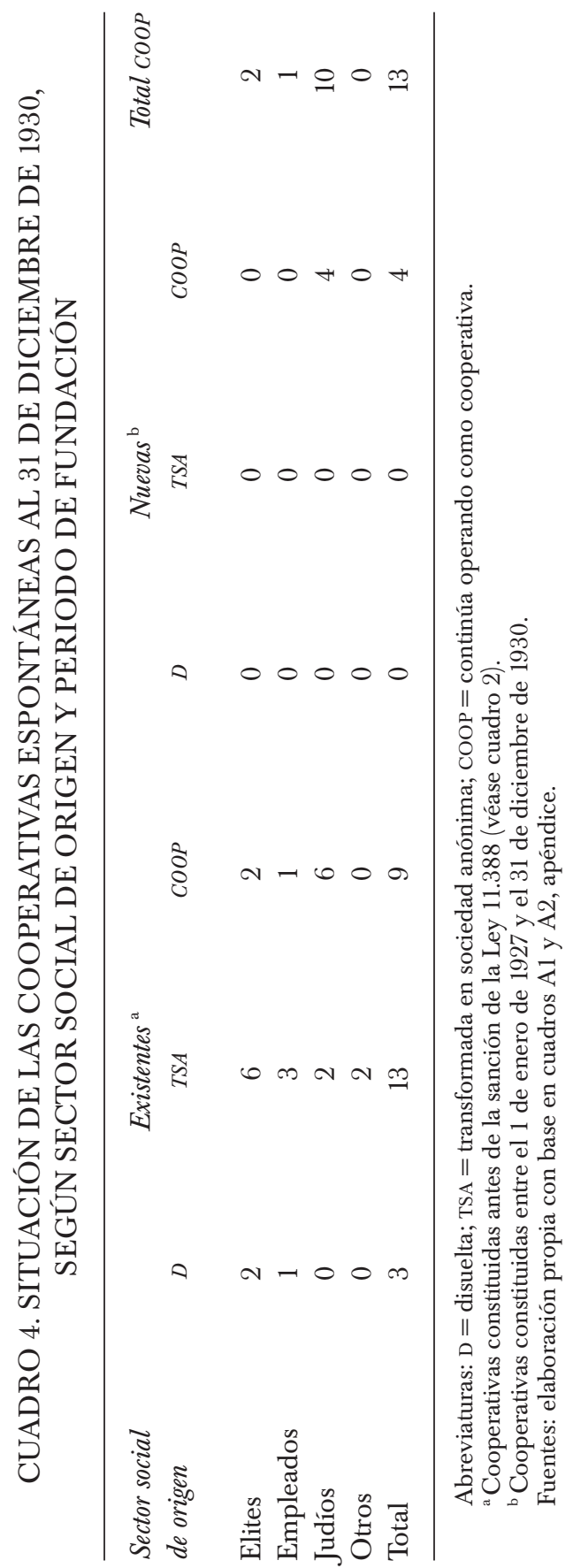


preeminencia sobre las actividades de intermediación financiera, y que la figura de la sociedad anónima haya sido considerada más idónea para el cumplimiento de tales funciones.

La situación de las cooperativas judías contrasta notoriamente con los grupos anteriores. Seis de las ocho entidades comprendidas en esta categoría continuaron operando bajo la forma cooperativa (véase cuadro 4, tercera columna). Al mismo tiempo, los incentivos económicos ofrecidos por la Ley 11.380 indujeron a la constitución como cooperativas de crédito de algunas instituciones de la colectividad que hasta ese momento habían operado de manera informal o bajo otras formas asociativas (cuadro 4, sexta columna y cuadro A2, Apéndice) ${ }^{29}$ Como resultado de esta evolución, hacia principios de la década de 1930 comenzaba a perfilarse una clara prevalencia de las entidades judías (cuadro 4, séptima columna); durante las décadas sucesivas esa tendencia se acentuaría gradualmente, y hacia fines de los años cincuenta las entidades de la colectividad liderarían un proceso de acelerada expansión del cooperativismo de crédito hacia otros segmentos de la sociedad argentina (Schujman, 1979).

\section{La excepcionalidad del cooperativismo de crédito de origen judio}

La particular reacción del cooperativismo de crédito judío ante las modificaciones normativas introducidas en 1926 merece dos consideraciones especiales. En primer lugar, la consagración del principio de neutralidad religiosa no afectó sustancialmente el funcionamiento de las entidades comprendidas en este grupo. Si bien debieron eliminar la palabra "israelita" de su denominación, durante mucho tiempo continuaron operando casi exclusivamente con miembros de la comunidad askenazí (Tiempo, febrero de 1985, núm. 189, pp. 8-10).

La actitud tolerante de las autoridades frente a la situación descrita parece reforzar la hipótesis de que la neutralidad religiosa apuntaba esencialmente a impedir el avance de las organizaciones católicas en el medio rural. Probablemente, también refleje el diverso papel que la religión desempeñaba al interior de estas organizaciones. Mientras las cajas rurales promovidas por la LSA habían sido parcialmente concebidas como herramienta para la difusión de un credo religioso, las cooperativas judías eran organizaciones nacidas en un proceso espontáneo, imbricadas en redes sociales en las que la religión actuaba como un mero elemento demarcatorio.

${ }^{29}$ Un ejemplo emblemático es el caso del Banco Industrial, que inició sus operaciones en 1917, pero se constituyó formalmente como cooperativa de crédito recién en 1929 (Quién es quién en la Argentina, 1939-1969). 
Un segundo aspecto importante que merece ser destacado tiene que ver precisamente con la imbricación de las cooperativas judías en un tejido social fuerte. Los inmigrantes askenazí que dieron vida a las primeras experiencias cooperativas habían radicado en colonias rurales y centros urbanos, siguiendo un patrón de enclave o gueto abierto (Feierstein, 2006, p. 147). La proximidad geográfica derivada de esta modalidad de asentamiento, sumada al sentimiento de identidad étnica y a los desafíos comunes que implicaba el proyecto migratorio, favoreció el establecimiento de vínculos personales y contribuyó al surgimiento espontáneo de prácticas de ayuda recíproca (Feierstein, 2006, pp. 129-130 y 148-149; Mirelman, 1990, pp. 43-45; Reula, 1969, pp. 262-265; Zadoff, 2005, pp. 134-135).

En esta línea de razonamiento, las experiencias de la colectividad judía pueden ser interpretadas como la manifestación, en un ámbito específico de la actividad económica, de relaciones de reciprocidad preexistentes en el ámbito social. La particular naturaleza de los vínculos interpersonales entre los socios cooperadores (capital social interno), y la estrecha relación de las cooperativas judías con el entorno socioeconómico en el que operaban (capital social externo) parecen haber determinado una rápida y eficaz adaptación al espíritu solidario consagrado por el marco jurídico de 1926. Probablemente, esos factores también hayan ejercido una influencia positiva sobre el desempeño económico de las cooperativas. ${ }^{30}$ La mayor parte de las entidades fundadas antes de la sanción de las leyes 11.380 y 11.388 tuvieron un largo y próspero recorrido en el sistema financiero argentino (véase cuadro 5). Cuatro de ellas llegaron a operar ininterrumpidamente durante más de cinco décadas; además, entre 1935 y 1942, tres de estas entidades fueron transformadas en bancos cooperativos, lo cual puede tomarse como indicador razonablemente fiable de la expansión del volumen de sus actividades económicas. ${ }^{31}$

\section{CONCLUSiOnes}

En la caracterización general ofrecida en este artículo, el cooperativismo de crédito anterior a 1926 emerge como un sector desarticulado y heterogéneo. A excepción de la creación de un sindicato de cajas rurales promo-

\footnotetext{
${ }^{30}$ Sobre la relación entre capital social y desempeño organizacional, véase, por ejemplo, Leana y Pil (2006).

${ }^{31}$ El decreto del poder ejecutivo nacional 15.130 del 21 de octubre de 1938, sentó las bases para una distinción entre cooperativas de crédito no bancarias (sujetas exclusivamente al régimen de la Ley 11.388) y bancos cooperativos (sujetos, además, a la Ley de Bancos 12.156 del 28 de marzo de 1935 y a la supervisión del recientemente creado Banco Central). En ese contexto, algunas de las cooperativas de mayor dimensión pasaron a operar como entidades bancarias.
} 


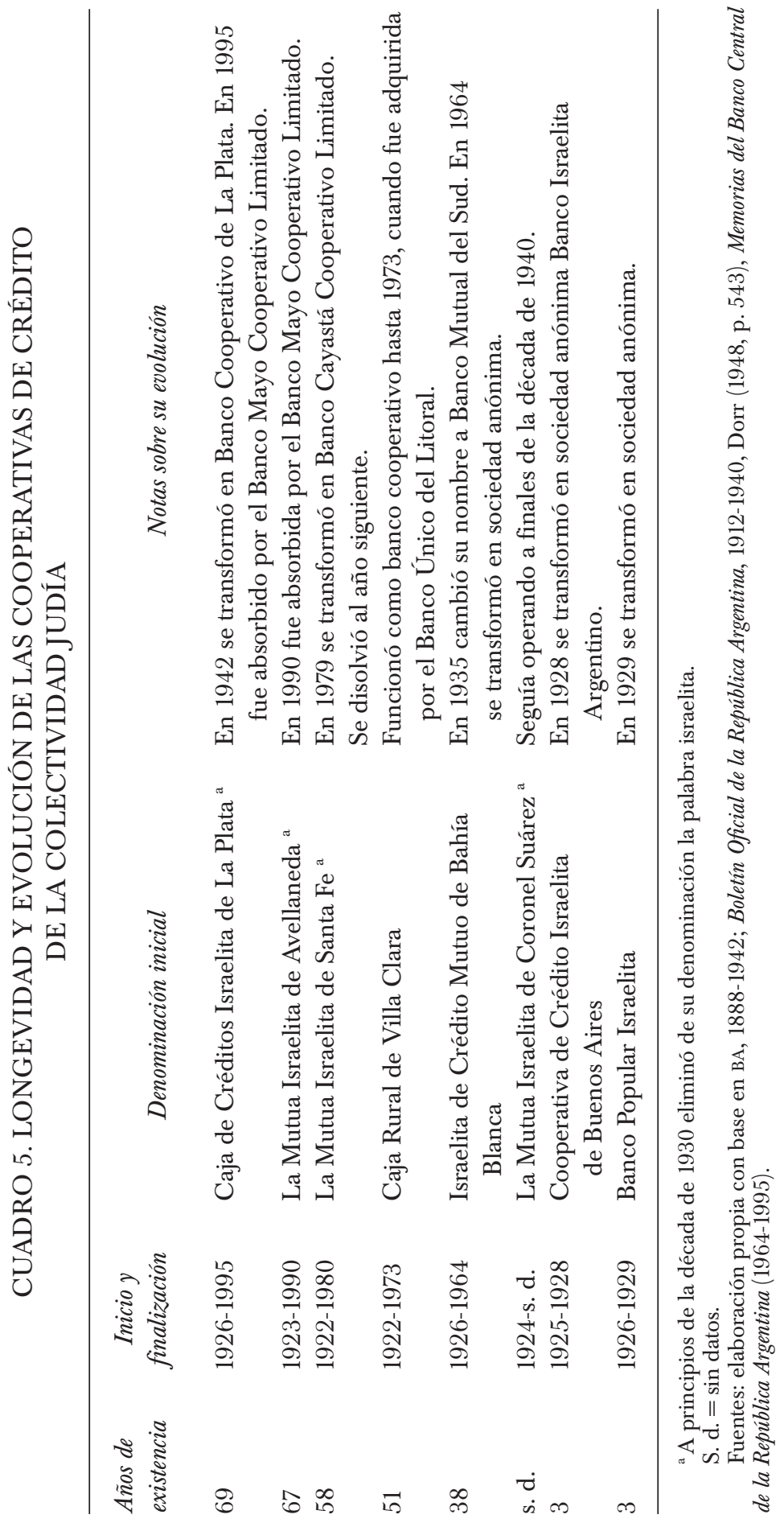


vido por la LSA, no existieron durante este periodo intentos de integración vertical. Si bien el número de entidades constituidas en forma espontánea fue considerable, estas operaron en forma aislada y no llegaron a conformar un movimiento.

El dinamismo de la actividad económica, la escasa regulación del sector financiero y la ausencia de disposiciones que estableciesen el carácter solidario de la cooperativa fueron factores que facilitaron el uso instrumental de la figura societaria. El elevado índice de transformaciones en sociedad anónima sugiere que muchos emprendimientos -particularmente entre las cooperativas constituidas por personajes vinculados a las elites económicas, políticas e intelectuales de la época- habrían estado parcial o plenamente inspirados por el afán de lucro. En el análisis desarrollado en este trabajo no se ha podido determinar el grado de incidencia de esas finalidades lucrativas sobre el universo de las cooperativas identificadas; tampoco ha sido posible establecer si la eventual persecución del lucro fue el fruto de una decisión premeditada, o bien el resultado de una progresiva desnaturalización de los objetivos societarios originales. La recopilación y el examen riguroso de las actas asamblearias de las sociedades transformadas queda como tarea pendiente para la elucidación de estas interrogantes.

Entre las sociedades inspiradas por propósitos solidarios, hubo varias que tampoco se ajustaron al modelo cooperativo tradicional. Las cooperativas formadas por empleados de una misma categoría profesional combinaron la intermediación financiera con otras funciones mutualistas; es posible que con el tiempo las operaciones del segundo tipo hayan ganado preeminencia, y que ello haya determinado una evolución de estas instituciones hacia otras figuras societarias. En el caso de las cooperativas inducidas por la LSA, los objetivos económicos se mezclaron con las funciones evangelizadoras. Si bien no lograron arraigarse, es probable que su experiencia haya sido determinante para la consagración del principio de neutralidad religiosa en el texto legal sancionado en 1926.

El hecho de que apenas nueve de las 94 cooperativas identificadas en este estudio hayan continuado su operación regular durante la década de 1930 podría considerarse -en una primera aproximación- como indicador de una escasa influencia de las experiencias pioneras sobre el desarrollo posterior de la cooperación de crédito en el país. El sentido de esta conclusión, sin embargo, puede cambiar radicalmente cuando se examina el origen social de las entidades que lograron trascender. Seis de las nueve cooperativas subsistentes estaban vinculadas a la colectividad judía; a pesar de la falta de una legislación adecuada, la imbricación social de esas organizaciones parece haber favorecido el desarrollo de intercambios cooperativos genuinos y estables. En este sentido, una hipótesis que cabría explorar en futuras investigaciones es que la tutela y los incentivos 
ofrecidos por el estado a partir de 1926 pueden haber contribuido a la institucionalización y a la expansión gradual de tales intercambios, sentando así las bases para el inicio de una etapa de extraordinario crecimiento. Aunque el análisis del desarrollo de este movimiento durante las décadas subsiguientes excede los objetivos del presente estudio, parece importante señalar que la cooperación judía se transformaría, hacia fines de los años cincuenta, en el motor de una rápida difusión del cooperativismo de crédito hacia otros sectores de la sociedad argentina. Bajo el liderazgo de dos federaciones cooperativas estrechamente ligadas a la colectividad askenazí, el número de entidades se multiplicaría exponencialmente y el sector llegaría a convertirse, hacia mediados de la década de 1960, en la principal fuente de financiamiento de la pequeña y mediana empresa nacional.

\section{APÉNDICE}

El cuadro A1 reporta 90 de las 94 cooperativas consideradas en el estudio. De acuerdo con Niklison (1920, p. 261) fueron fundadas 33 cajas rurales (inducidas), pero las fuentes consultadas sólo han permitido identificar 29. Por su parte, el cuadro A2 reporta las cooperativas de crédito constituidas durante los primeros cuatro años de vigencia del régimen legal sancionado entre octubre y diciembre de 1926.

Para las cooperativas incluidas en los grupos elites, judios, empleados y otros se reporta la denominación social, seguida por un paréntesis que indica, en primer término, el año de obtención de la autorización para funcionar y, en segundo término, el año de desaparición de la sociedad, seguido por una sigla que indica las causas (TSA = transformada en sociedad anónima; $\mathrm{D}=$ disuelta; s. d. = sin datos). En el caso de las entidades disueltas, el año reportado corresponde a la fecha de retiro de la autorización para funcionar (no siempre coincidente con la fecha de finalización efectiva de las operaciones). Para algunas sociedades se desconoce el año preciso de disolución, pero se sabe que ya no operaban al momento de sanción de la Ley de Cooperativas de 1926; en dichos casos, el año de disolución se reporta como "a.1926". La sigla COOP, por su parte, indica que la entidad continuó operando como cooperativa durante la década de 1930. En el caso de las cajas rurales (inducidas) se reporta la localidad de fundación, seguida por el año de inicio de las operaciones. 


\section{CUADRO A1. COOPERATIVAS DE CRÉDITO CONSTITUIDAS ENTRE 1887 Y 1926}

\section{ESPONTÁNEAS}

Elites

Banco Popular Argentino (1887, 1927, TSA); Banco Popular de Buenos Aires (1887, 1900, D); Banco de Roma y Río de la Plata (1889, 1894, D); Caja Cooperativa de Créditos y Ahorros (1889, a.1926, D); Banco Popular Italiano (1898, 1908, TSA); Banco Popular de Rosario (1899, 1908, TSA); El Hogar Argentino (1899, 1915, TSA); Banco Popular de San Juan (1900, s. d.); Banco Popular de Esquina (1902, s. d.); La Alianza (1903, 1914, D); Caja Económica de San Nicolás (1903, 1929, TSA); Banco Popular de Concordia (1903, 1909, TSA); Banco Popular Español (1904, 1906, TSA); Banco de Crédito Dotal (1904, 1906, TSA); ${ }^{\text {b } B a n c o ~ P o p u l a r ~ d e ~ S a n ~ N i c o l a ́ s ~(1904, ~ 1911, ~ D) ; ~ B a n c o ~}$ Industrial y Comercial de Mendoza (1904, a.1926, D); Banco del Este (1904, a.1926, D); Banco Popular de Mendoza (1905, a.1926, D); Banco Mercantil de la América de Sud (1906, 1913, TSA); La Casa Popular Propia (1906, COOP); Banco Escolar Argentino del Rosario (1906, 1922, TSA); La Alcancía Popular (1907; 1910, D); El Hogar Obrero (1907, COOP); Banco Familiar (1907, 1928 TSA); Banco Industrial Río de La Plata (1907, 1915, D); Banco Popular de Junín (1907, 1927 D); Banco Basko Argentino (1908, 1914, D); Banco Universal (1909; 1910, D); Banco el Hogar Propio (1910, 1927, TSA); Los Previsores (1910, 1913, D); Banco Gremial de Buenos Aires (1913, 1916, D); Banco Popular de Saladas (1914, s. d.); Banco Popular de Misiones (1918, 1930, TSA); La Americana (1923, 1927 D); El Previsor Argentino (1923, 1924 TSA); Banco Cooperativo del Chaco (1924, 1930 TSA).

\section{Judíos}

Caja Rural de Villa Clara (1922, COOP); La Mutua Israelita de Santa Fe (1922, COOP); La Mutua Israelita de Avellaneda (1923, COOP); La Mutua Israelita de Coronel Suárez (1924, COOP); Cooperativa de Crédito Israelita de Buenos Aires (1925, 1928, TSA); Israelita de Crédito Mutuo de Bahía Blanca (1926, COOP); Banco Popular Israelita (1926, 1929, TSA); Caja de Créditos Israelita de La Plata (1926, COOP).

\section{Empleados}

Banco Escolar Argentino (1904, 1927, TSA); Banco Policial Argentino (1912, 1926, TSA); Cooperativa de Empleados de Banco (1913, 1929, TSA); Banco Escolar Entrerriano (1916, a.1926, D); Crédito Popular Ferroviario (1920, 1928, D); La Recíproca Sociedad Mutual Cooperativa entre Empleados de las Obras Sanitarias de la Nación (1923, 1928, TSA); Banco Ceres, Cooperativa entre Empleados del Ministerio de Agricultura (1924, COOP). 


\section{Otros}

Banco Popular de Tandil (1887, 1887, D); ${ }^{a}$ Banco Popular de La Plata (1904, 1927, TSA); Banco Previsor de Ahorro (1905, 1924, D); Banco Popular de Pergamino (1906, 1916, D); Banco Comercial Agrícola de Pergamino (1907, a.1926, D); Banco El Ahorro Internacional (1908, 1911, D); Banco Económico Argentino (1910, 1929, TSA); Banco Internacional del Plata (1912, 1917, D); El Hogar Italo Argentino (1912, s. d.); Caja Popular de Concordia (1913, s. d.).

\section{INDUCIDAS}

Jovita (1912, s. d., D); Colonia Caroya (1912, s. d., D); Roldán (1912, s. d., D); San José de La Esquina (1912, s. d., D); Resistencia (1912, s. d., D); Arteaga (1912, s. d., D); Colonia Vignaud (1912, s. d., D); Cabrera (1913, s. d., D); La Playosa (1913, s. d., D); Sampacho (1913, s. d., D); Marcos Juárez (1913, s. d., D); El Trébol (1913, s. d., D); Arribeños (1914, s. d., D); Rawson (1914, s. d., D); Centeno (1914, s. d., D); Colonia Ana (1914, s. d., D); O’Higgins (1915, s. d., D); Chacabuco (1915, s. d., D); Acebal (1915, s. d., D); Carcarañá (1915, s. d., D); Conchitas (1915, s. d., D); San José de Quilancita (1915, s. d., D); Colonia Carolina (1916, s. d., D); Zavalla (1916, s. d., D); Villa Gobernador Gálvez (1916, s. d., D); Serodino (1916, s. d., D); Noetinger (1918, s. d., D); Federación (1921, s. d., D); Bulnes (s. d., D)

${ }^{a}$ Constituido formalmente como sociedad anónima, cuando aún no existía una tipificación legal de la figura cooperativa.

${ }^{\mathrm{b}}$ Cambia su denominación por Banco de Crédito Argentino.

c Cambia su denominación a Banco Nacional Popular y, sucesivamente, a Banco Franco Argentino de Descuentos.

Fuentes: Agote (1881-1888); Personerías Jurídicas, exps. 149-P-5, 234-P-8, 5655-S-20, Archivo General de la Provincia de Santa Fe; Almanaque (1937); Alonso y Guspi (2005); Anuario Kraft (1942); Anuario Veritas (1948); Auza (1987); BA (1888-1942); Banco Popular de Rosario (1978); Bassi (1905); Boletín Oficial de la Bolsa de Comercio de Buenos Aires (1930-1935); Boletín Oficial de la República Argentina (1912-1940); Borea (1917); Caras y Caretas (1898-1939); Carranza (1904-1912); Chervo y Magliarini (2010); Comisión Nacional del Censo (1917); Corrientes (1938); Dirección de Agricultura Ganadería e Industrias (1935); Devoto (2008); Dimarco (1993); Dirección General de Estadística (1926); Dirección General de Estadística Municipal (1891-1914); Dorr (1948); Escalante (1913); Fray Mocho (1912); Hilton (1950); La Nación Argentina (1916); Lhande (1909); Medina (2004); Memorias del Banco Central de la República Argentina (1964-1995); Ministerio de Justicia e Instrucción Pública (1887-1929); Museo Social Argentino (1916, 1920, 1921); Quesada (1901); Quién es quién en la Argentina (1939-1969); RA (1888-1938, 1897-1911); Repetto (1944); Reula (1969); Revista ilustrada de banca (1896-1936); Richard-Jorba (2008); Serralunga (1920a, 1920b); Tenembaum (1946); The Argentine Yearbook (1902-1915); The Review of the River Plate (1923-1925); Varese y Arias (1966); Vida Financiera (1913-1933). 


\section{CUADRO A2. COOPERATIVAS DE CRÉDITO CONSTITUIDAS ENTRE 1927 Y 1930}

\section{ESPONTÁNEAS}

Elites

\section{Judios}

Caja de Crédito Mutuo Cooperativa Limitada de Paraná (1927, COOP); Banco Mutual de Créditos de La Plata (1927, COOP); Cooperativa Popular de Créditos Mutuos de Rosario (1929, COOP); Banco Industrial Sociedad Cooperativa Limitada (1929, COOP).

\section{Empleados}

$-$

Otros

$-$

\section{Inducidas}

Fuentes: Personerías Jurídicas, exp. 9641, Archivo General de la Provincia de Santa Fe; Bokser de Liwerant, Gojman y Soriano (1999); Boletín Oficial de la República Argentina (1912-1940); BA (1888-1942).

\section{LISTA DE REFERENCIAS}

Accose, D. (1935). El crédito agrario en la República Argentina (Tesis doctoral). Buenos Aires, Universidad de Buenos Aires.

Adelman, J. (1990). Agricultural credit in the province of Buenos Aires, Argentina, 1890-1914. Journal of Latin American Studies, 22(1-2), 69-87. DOI: 10.1017/ S0022216X0001511X

Agote, P. (1881-1888). Informe del presidente del Crédito Público Nacional sobre la deuda pública nacional, bancos, acuñación de moneda, y presupuestos y leyes de impuestos de la nación y de las provincias (vols. 1-5). Buenos Aires: Guillermo Kraft.

Almanaque del mensajero (1937). Buenos Aires: Talleres Jacobo Peuser Ltda.

Alonso, S. y Guspí, M. (2005). Historia genealógica de antiguas familias italianas de Rosario, 1870-1900. Rosario: Instituto Italiano.

Anuario Kraft (1942). Buenos Aires: Guillermo Kraft.

AuZA, N. (1987). Aciertos y fracasos sociales del catolicismo argentino (vol. 2). Buenos Aires: Docencia. 
Ballent, A. (1988). El hábitat de los sectores populares: el caso de El Hogar Obrero (Seminario de crítica, 4). Buenos Aires: Instituto de Arte Americano e Investigaciones Estéticas. Recuperado de http://www.iaa.fadu.uba.ar/publicaciones/critica/0004.pdf

Bassi, A. (1905). La escuela experimental de Esquina (vol. 1). La Plata: Talleres Gráficos Sesé y Larrañaga.

Becco, P. (1938). Fomento de la cooperación agropecuaria. Buenos Aires: Talleres Gráficos Ferrari Hnos.

Birchall, J. (2013). Resilience in a downturn: The power of financial cooperatives. Geneva: International Labour Office.

Bokser de Liwerant, J., Gojman, A. y Soriano, H. (1999). Encuentro y alteridad: vida y cultura judía en América Latina. México: Universidad Nacional Autónoma de México.

Bonaparte, H. (1989). Proceso y significado del cooperativismo argentino. En ComiSión Económica para América Latina y el Caribe (ed.), Cooperativismo latinoamericano: antecedentes y perspectivas (pp. 41-94). Santiago de Chile: Autor.

BoreA, D. (1917). La mutualidad y el cooperativismo en la República Argentina. En Comisión Nacional del Censo (ed.), Tercer censo nacional (vol. 10, pp. 85-239). Buenos Aires: Talleres Gráficos de L. J. Rosso y Cía.

Brauner, S. (2007). La Federación Argentina de Cooperativas de Crédito y sus prácticas políticas (1950-1966). Revista OIDLES, 1(1), 584-597. Recuperado de http:// www.eumed.net/rev/oidles/01/Brauner.htm

Bravo, M. (1927). Informe de la Comisión de Códigos. En Congreso NaCional (ed.), Diario de Sesiones de la Cámara de Diputados, año 1926 (vol. 5) (pp. 203-242). Buenos Aires: Compañía Sud-Americana de Billetes de Banco.

Buenos Aires [BA] (1888-1942). Registro Oficial de la Provincia de Buenos Aires. La Plata: Taller de Impresiones Oficiales.

Carranza, A. (1904-1912). Anuario financiero-administrativo de la República Argentina (vols. 1-8). Buenos Aires: Compañía Sud-Americana de Billetes de Banco.

Cavallone, A. (1947). Cooperativismo: sociedades cooperativas en la República Argentina. Buenos Aires: SEMCA.

Chervo, S. y Migliarini, M. (2010). Historia de San Nicolás de los Arroyos y su pago. San Nicolás: El Norte Editora y Periodística.

Comisión Nacional del Censo (ed.) (1917). Tercer censo nacional (vol. 10). Buenos Aires: Talleres Gráficos de L. J. Rosso y Cía.

Congreso Nacional (1904). Diario de sesiones de la Cámara de Diputados. Año 1904 (vol. 2). Buenos Aires: Imprenta del Congreso de la Nación.

Congreso Nacional (1916). Diario de sesiones de la Cámara de Diputados. Año 1915 (vol. 3). Buenos Aires: Talleres Gráficos de la Gaceta de Buenos Aires.

CORRIENTEs (1938). Memoria de la acción administrativa correspondiente al ejercicio del Año 1937. Corrientes: Imprenta del Estado. 
Della Paolera, G. y TaYlor, A. (2001). Straining at the anchor: The Argentine Currency Board and the search for macroeconomic stability, 1880-1935. Chicago: Chicago University Press.

Devoto, F. (2008). Historia de los italianos en Argentina. Buenos Aires: Biblos.

Dimarco, R. (1993). Manual de historia de Junín. Buenos Aires: Ediciones Salido.

Dirección de Agricultura Ganadería e Industrias (1935). Anuario rural de la Provincia de Buenos Aires (vol. 3). La Plata: Taller de Impresiones Oficiales.

Dirección General de Estadística (1926). Censo bancario de la República Argentina 1925. Buenos Aires: Guillermo Kraft.

Dirección General de Estadística Municipal (1891-1914). Anuario estadístico de la ciudad de Buenos Aires. Buenos Aires: Compañía Sud-Americana de Billetes de Banco.

DorR, A. (ed.) (1948). Guía de sociedades anónimas, responsabilidad limitada y cooperativas 1945-1947. Buenos Aires: s. e.

Escalante, W., Zeballos, E., Basualdo, B., Colombres, E. (1889). Informe de la Comisión Reformadora a la Honorable Cámara de Diputados. En RePúbliCA ARgentina (ed.), Código de Comercio de la República Argentina (pp. VII-LXXXI). Buenos Aires: Imprenta La Universidad.

Escalante, M. (1913). Los hombres de la América del Sud. Madrid: Imprenta Artística Española.

Feierstein, R. (2006). Historia de los judios argentinos. Buenos Aires: Galerna.

FERreres, O. (2005). Dos siglos de economía argentina, 1810-2004: historia argentina en cifras. Buenos Aires: El Ateneo.

GLEIZER, A. (1981). La experiencia del movimiento cooperativo de crédito en la República Argentina como instrumento de transformación económica y social. Revista Idelcoop, 8(31), 429-448. Recuperado de http://www.idelcoop.org.ar/sites/default/ files/revista/articulos/pdf/81040203.pdf

Grela, P. (1965). Cooperativismo y monopolio. Buenos Aires: Platina.

Hilton, R. (ed.) (1950). Who's who in Latin America (vol. 5). Stanford: Stanford University Press.

JACOB, E. (2004). Classification and categorization: A difference that makes a difference. Library Trends, 52(3), 515-540.

Kalmi, P. (2013). Cooperative Banking. En J. Toporowski, y J. Michell (eds.), Handbook of critical issues in finance (pp. 56-65). Cheltenham: Edward Elgar.

Kampel, D. y VuotTo, M. (2000). La banca cooperativa en Argentina: su desempeño entre 1993 y 1999 (Documento de trabajo, 24). Recuperado de www.econ.uba.ar/cesot/ docs/documento\%2024.pdf

La Nación Argentina (1916). Buenos Aires: Coni Hermanos.

LEANA, C. y PIL, F. (2006). Social capital and organizational performance: Evidence from urban public schools. Organization Science, 17(3), 353-366. DOI: 10.1287/ orsc.1060.0191

LHANDE, P. (1909). L'émigration basque. Revue Internationale des études basques, III, 79-100. 
LóPez, C. (1987). Cooperativismo y cultura: historia de Villa Domínguez, 1890-1940. Entre Ríos: Editorial Entre Ríos.

Macpherson, I. (1995). Co-operative Principles for the 21st Century. Geneva: International Co-operative Alliance.

Medina, L. (2004). Recopilación histórica de Concordia. Concordia: Grafelco.

Ministerio de Justicia e Instrucción Pública (1887-1929). Memoria presentada al Congreso Nacional (Anexos de Justicia, varios vols.) Buenos Aires: Taller Tipográfico de la Penitenciaría Nacional y Talleres Gráficos Argentinos de L. J. Rosso y Cía.

Mirelman, V. (1990). Jewish Buenos Aires, 1890-1930: In Search of an Identity. Detroit: Wayne State University Press.

Mizrahi, M. (1976). Cooperativas de crédito: naturaleza, desarrollo, régimen legal, propuesta de cambio. Buenos Aires: Depalma.

Moirano, A. (1948). La cooperación en Argentina. Boletín del Museo Social Argentino, 307-308, 1-17.

Museo Social Argentino (1916). Banco Escolar Entrerriano. Boletín del Museo Social Argentino (año v, 57-58), 477-482.

Museo Social Argentino (1920). Primer Congreso de la Cooperación. Buenos Aires: Establecimiento Gráfico Oceana.

Museo Social Argentino (1921). Nómina completa de las Sociedades Cooperativas existentes en la República Argentina. Boletín del Museo Social Argentino, 9, 151-165.

Nakamura, L. y ZaraZaga, C. (2001). Banking and finance in Argentina in the period 1900-35 (Working Paper, 01-7). Filadelfia: Federal Reserve Bank of Philadelphia.

Niklison, J. (1920). Acción social católica obrera. Boletín del Departamento Nacional del Trabajo, 46, 1-286.

PLOTINSKY,D.(2011).Cooperativismoydictadura:delascajasdecréditoalosbancoscooperativos, (1976-1979). Revista Idelcoop, 38(202), 28-44. Recuperado de http://www.idelcoop.org.ar/ revista/202/cooperativismo-y-dictadura-1976-1979-cajas-credito-bancos-cooperativos

Quesada, S. (1894). El Banco Hipotecario de la Provincia de Buenos Aires. Buenos Aires: Martín Biedma.

Quesada, S. (1901). Historia de los bancos modernos: banco de descuentos, la moneda y el crédito (vol. 2). Buenos Aires: M. Biedma e Hijo.

Quién es quién en la Argentina (1939-1969). Buenos Aires: Guillermo Kraft.

Repetto, N. (1932). Lecciones sobre cooperación. Buenos Aires: La Vanguardia.

Repetto, N. (1944). Cómo nace y se desarrolla una cooperativa. Buenos Aires: A. Giménez.

República Argentina (ed.) (1889). Código de Comercio de la República Argentina. Buenos Aires: Imprenta de la Universidad.

República Argentina [RA] (1888-1938). Registro nacional de la República Argentina (vols. correspondientes al periodo 1887 a 1911). Buenos Aires: Taller Tipográfico de la Penitenciaría Nacional.

República Argentina [RA] (1897-1911). Registro nacional de la República Argentina que comprende los documentos expedidos desde 1810 hasta 1891 (vols. 11-14). Buenos Aires: Taller Tipográfico de la Penitenciaría Nacional. 
República Argentina (1902). Informe de los consejeros legales del Poder Ejecutivo correspondiente a los años 1892 y 1893 (vol. 10). Buenos Aires: Taller Tipográfico de la Penitenciaría Nacional.

Reula, F. (1969). Historia de Entre Ríos: política, étnica, económica, social, cultural y moral (vol. 2). Entre Ríos: Castellví.

Richard-Jorba, R. (2008). Los empresarios y la construcción de la vitivinicultura capitalista en la provincia de Mendoza (Argentina), 1850-2006. Scripta Nova, 12(271), 741-798. Recuperado de http://www.ub.edu/geocrit/sn/sn-271.htm

Rodríguez, A. (1975) Historia de la policía federal argentina. Buenos Aires: Editora Policial.

Rosso, O. (1942). Las asociaciones de cooperación y crédito popular. Revista de Ciencias Económicas, 249, 331-347.

Rougier, M. (1999). El financiamiento bancario a las empresas industriales en la Argentina: antecedentes y orígenes del Banco de Crédito Industrial Argentino. Estudios Interdisciplinarios de América Latina, 10(2), 37-62. Recuperado de http://eial.tau. ac.il/index.php/eial/article/view/1007

Schujman, L. (1979). Credit cooperation and its contribution to development. Santa Fe: Idelcoop.

SEGUí, F. (1898). Investigación parlamentaria sobre agricultura, ganadería, industrias derivadas y colonización (anexo B). Buenos Aires: Taller Tipográfico de la Penitenciaría Nacional.

SEIJO, F. (1937). Algunas sugestiones acerca de lo que podría hacerse en materia de mutualidad y previsión social. Boletín de Obras Sanitarias de la Nación, 1(5), 533-541.

SERralunga, G. (1920a). Las cajas rurales tipo Raiffeisen y los arrendamientos directos y colectivos como remedio al malestar agrario y base de la nueva colonización argentina. En Congreso Nacional (ed.), Diario de Sesiones de la Cámara de Senadores (vol. 1) (pp. 475-480). Buenos Aires: Establecimiento Gráfico de A. Martino.

SERralunga, G. (1920b). Sobre cooperación en general y agrícola en particular. Estudios, 19(4), 265-272.

Tenembaum, J. (1946). Orientación económica de la agricultura argentina. Buenos Aires: Losada.

TERRY, J. (1894). Informe sobre los bancos locales en las provincias y territorios nacionales. Buenos Aires: Compañía Sudamericana de Billetes de Banco.

The Argentine Yearbook (1902-1915). Buenos Aires: John Grant \& Son.

VArese, C. y Arias, H. (1966). Historia de San Juan. Mendoza: Spadoni.

VERBEKE, G. (2005). Las transformaciones de la estructura del sector cooperativo de ahorro y crédito en la Argentina: el caso de las cajas de crédito, 1996-2005 (Tesis de maestría). Universidad Nacional de General Sarmiento, Argentina.

ZADOFF, E. (2005). Crédito económico y liderazgo comunitario: las cooperativas de crédito judías y la vida comunitaria judía argentina en el siglo XX. En J. GolDSTiEn, F. Goldberg, E. ZAdoff (eds.), Judaica Latinoamericana: Estudios HistóricoSociales (vol. v) (pp. 129-144). Jerusalem: Universitaria Magnes. 


\section{FUENTES PRIMARIAS}

\section{Archivos}

Archivo General de la Provincia de Santa Fe, Personerías Jurídicas. Ministerio de Gobierno y Reforma del Estado, Gobierno de Santa Fe, Argentina. [AGPSF] http:// gobierno.santafe.gov.ar/archivo_general/perso_juri/index.php?template=Consul ta\&controlador $=$ ConsAvanzada

\section{Hemerografía}

Anuario Veritas, Buenos Aires, 1948.

Banco Popular de Rosario, memoria y balance general correspondiente al $78^{\circ}$ ejercicio, Rosario, 1978.

Boletín Oficial de la República Argentina [BORA], Buenos Aires, 1912-1940.

Boletín Oficial de la Bolsa de Comercio de Buenos Aires, Buenos Aires 1930-1935.

Caras y Caretas, Buenos Aires, 1898-1939.

Crisol, Buenos Aires, 1920-1921.

La Civiltà Cattolica, Roma, 1913.

Fray Mocho, Buenos Aires, 1912.

Memorias del Banco Central de la República Argentina, Buenos Aires, 1964-1995.

The Review of the River Plate, Buenos Aires, 1923-1925.

Revista Ilustrada de Banca, Ferrocarriles, Industria y Seguros, Madrid, 1896-1936.

Tiempo, Buenos Aires, 1985.

Vida financiera, Madrid, 1913-1933. 